The National Library supplies copies of this article under licence from the Copyright Agency Limited (CAL). Further reproductions of this article can only be made under licence.

\title{
Schmalz is as Schmalz Does: Sentimentality and Picture Books
}

\author{
Clare Bradford
}

W

hen the terms 'sentimentality' and 'sentimental' appear in critical writing on children's literature, they are generally treated as though they encode a universally-accepted set of signifieds, located around ideas relating to an excess of or lack of control over emotion and to manipulative discoursal strategies. But the sentimental is not so easily pinned down, being imbricated in ideological clusters intersected by class, education, gender and cultural contexts. What is seen to be acceptable in cultural representations of sentiment shifts and changes along with shifting discursive and social practices, and signals interesting fissures and contradictions; for example, the sentimentalisation of child characters in many Victorian novels coincides with a time when thousands of children were condemned to various occupational diseases and to death through the widespread practice of child labour in English factories and mines. Moreover, notions of sentimentality are to a large extent culturally-dependent and relate to those ideas of national identity which, in Richard White's words, 'are invented within a framework of modern Western ideas about science, nature, race, society, nationality' (1981, p.ix). The idea of the 'typical Australian' promulgated by the Bulletin writers and still influential in popular mythology is, for instance, strongly antisentimental, privileging 'masculine' qualities of toughness, mateship and antiauthoritarianism, and relegating sentimentality to the realm of the feminine; in such a context, the label 'sentimental' is enough to ascribe inferiority to that which is so labelled, unless, as with Dennis's Sentimental Bloke, sentimentality is treated ironically to encode the inarticulateness of the stereotypically strong, silent hero.

The common association of the term 'sentimentality' with a lexical set of terms such as 'emotion', 'feeling' and 'affectivity' constitutes a reminder, if one is needed, of the gendered assumptions which work through binary oppositions such as those of reason/emotion; public/private; head/heart, to privilege the masculine (encoded in the first term of each binary) over the feminine. A discussion of sentimentality runs the risk of subsuming the notion of sentimentality within that of emotion, and thereby seeming to affirm the distrust of affectivity which permeates patriarchal discourse. The question which remains, therefore, is how sentimentality is to be defined, and especially how it might be seen in relation to emotion.

I alluded earlier to the most prominent of the discursive features through which sentimentality is realised: an excess of or lack of control over emotion. But the sentimental is not simply a matter of discourse which may be seen as cloying or excessive in its encoding of emotion; more fundamentally, it is embodied in the interactions between implied author or narrator and implied reader or narratee, and particularly in narrative strategies which seek to manipulate subjectivity. The following anecdote may serve as a means of broaching some ideas about sentimentality and the sentimental. Several years ago, I attended a seminar at which Ken and Yetta Goodman, two eminent scholars and activists in the field of literacy education, gave a joint presentation to a group of teachers, librarians and academics. In what appears, in retrospect, a powerfully gendered division of labour, Ken Goodman outlined his approach to the theory and practice of literacy education and Yetta Goodman. read the audience Robert Munsch's highly sentimental picture book text Love You Forever, whose narrative deals with the relationship between a mother and her son, from the son's birth to the mother's old age. I do not recall how this reading was introduced or what reasons were given for its presentation, but I have vivid memories of its effect on its audience as the sounds of weeping filled the lecture-theatre. 
It seemed to me at the time that while the emotions evoked (grief, sadness, guilt, sympathy) related experientially to the lives of the participants (most of whom were middle-aged women who might be expected to have aging parents), the consequence of the reading was to focus upon the figure of Yetta Goodman as the catalyst for these emotions and to endow her with a kind of reflected wisdom, goodness and authority. This, I think, offers the premise that sentimentality in picture book texts might have a similar effect: the deflection of emotion onto the figure of a narrator or implied author, rather than on the capacity of the text to create for its reader a subject position which enables her to draw upon her own emotional experience so as to derive significance out of textual representations of emotion. In the episode I have described, Yetta Goodman performatively appropriated the narrative voice of Love You Forever, and my discussion will focus on the discursive construction of voice in several picture book texts.

Some of the ways in which sentimentality is realised in illustrations and design are obvious: idealised representations of children or furry animals, for example, featuring close-ups of round faces, large eyes, long eyelashes; the use of soft pastel colours to evoke a mood of nostalgia or sweetness; an overreliance on motifs and images such as flowers and hearts. Again, however, the dividing-line between illustrations which encode emotion and those which are sentimental is not always clear, for as Jane Doonan notes, 'The danger of describing images set down with tenderness is that sentimentality may be implied, a saccharine strand detectable in too many children's picture books' (1994, p.167). And in some picture books, as I will argue, illustrations which are not in themselves sentimental are driven by texts which, to some degree, draw visual images into sentimental narrative frames.

The next section of this discussion considers three picture books which thematise the death of grandparents or surrogate grandparents: John Burningham's Granpa (1984), Mem Fox and Craig Smith's Sophie (1989) and Dyan Blacklock and Steven Woolman's The Lighthouse (1995). Both Granpa and Sophie construct strong emotional bonds between granddaughters (Sophie and the unnamed child protagonist of Granpa) and their grandfathers; both encode these emotional bonds on their front covers through images of physical closeness and intimacy, and in each case the motif of the grandfather's empty chair is used to represent death. The time spans in the two books are quite different; while that of Granpa covers a period from before Granpa's illness to just after his death, that of Sophie extends from just before Sophie's birth to the birth of her own daughter, so incorporating a period of between two and three decades.

Granpa has often been praised for the dialogic complexity with which Burningham constructs a close and loving relationship while foregrounding the different experiential and imaginative worlds which the two characters inhabit (see Bradford 1994, p.206; Graham 1990, pp.108-117; Watson 1996, pp.80-100). Intimations of Granpa's mortality are first evoked against the wintry background of a snow-covered hill (pp.24-25), through the following dialogue:

Harry, Florence and I used to come down that hill like little arrows.

I remember one Christmas...

You nearly slipped then, Granpa.

The sepia drawing on the lefthand page represents Granpa's memory of Harry, Florence and himself speeding down the hill, while the ink-and-wash illustration of the right-hand page represents his elderly self, walking carefully and supported by his granddaughter (Plate 1. p.27). The juxtaposition of these images contrasts the physical energy and confidence of Granpa's youthful self with the physical uncertainty 
(encoded through his outstretched arm, clutching his granddaughter's hands) of old age; as well, it effects a link between her and the child he once was, so paving the way for a view of death which incorporates continuity as well as loss.

This pivotal point in the narrative builds on a sequence in which Granpa and his granddaughter engage companionably in various kinds of activities, ranging from gardening to a teaparty for toys, and including a scene in which the two are temporarily estranged; the links between the sepia past and the coloured present and Burningham's careful selection of telling details in the illustrations work to construct a rich and complex set of interactions, so that when the rhythms of the narrative are disrupted by Granpa's illness the reader is afforded a context in which to understand the emotional significance of such disruption. The wordless doublespread in which the child, hunched on a chair, looks across an expanse of white space at her grandfather's empty chair thus evokes not only loss and absence but also the memory of his presence and of shared experiences, and the final (again, wordless) page, in which a young girl pushes a baby in a pram up a hill, constructs an overall mood of energy and optimism encoded by the colours of sun and sky and by the determined line of the girl's movement.
The death of Sophie's grandfather in Sophie is prefigured from the first lines of verbal narrative, since behind the temporal scheme encoded in 'Once there was no Sophie. And then there was' is shadowed another temporal scheme: 'Once there was [Grandpa]. And then there was not', or, for that matter, 'Once there was [Sophie]. And then there was not.' In this way the text is loaded with premonition; it is loaded, too, with syntactic echoing and variation which represents old age as the inverse of youth: 'Grandpa and little Sophie loved each other...Sophie and little Grandpa loved each other'; 'Sophie's hand curled round Grandpa's

finger...Grandpa's hand held on to Sophie's.' The effect of this patterning (and of explicit statements of affectivity such as 'Grandpa and little Sophie loved each other') is to delimit interpretative possibilities; the narrative voice is so explicit and so knowing as to create a relatively passive subject position.

Moreover, the narrative insistence on Grandpa's becoming smaller and slower constructs old age in terms of diminution and loss, so that the aging Grandpa is seen as an elderly child, the object of Sophie's attention and care. Craig Smith's illustrations, with their edge of caricature, might have been expected to provide an astringent counterpoint to the sentimentality of the text, but in the main they reinforce the narrative line, here and there hinting at ironic possibilities such as that suggested by the photograph of Queen Elizabeth located over the 'happy family' scene after Sophie's birth (pp.4-5).

The empty chair in Sophie is not allowed to speak for itself but must be interpreted by the narrative voice: 'And then there was no Grandpa' (pp.23-29); again, emotion is handed to the reader as on a platter: 'just emptiness and sadness for a while' (pp.30-31). The book's ending, in which the hand of Sophie's baby clings to its mother's finger, forces a peculiarly unsatisfying closure, since the text's reliance on syntactic echoing produces the inference that Sophie's hand will one day cling to that of Sophie's newly-born baby (as Grandpa's hand clung to Sophie's), and so on in a constant pattern of youth and age, birth and death. In itself this is a relatively banal idea, and since neither text nor illustrations work to concretise sufficientiy the relationship between Grandpa and Sophie, the final impact is that of a generalised and muted sadness. Sophie is, I think, sentimental for several reasons: an over-use of descriptors such as 'Little' and 'tiny'; a reliance on syntactic echoing which is portentous rather than expressive; and an insistence on telling the reader how to feel. It is the last of these features which most closely accords with my 
premise that sentimentality is realised in picture book narratives through a deflection of emotion onto the figure of a narrator, for in Sophie it is, finally, the voice of the narrator which prevails; a voice which by claiming an exclusive access to emotion invalidates the reader's experience.

I have selected The Lighthouse as the third in this group of texts because it demonstrates a sentimentality realised more through illustrations and design than through text. The firstperson narrative, focalised through an eight-year-old child for whom Mr and Mrs Mayman act as surrogate grandparents, deals with the dilemma of old $\mathrm{Mr}$ Mayman when his wife dies and his grief renders him incapable of preserving the elaborate topiary of his garden, which is clipped to resemble waves and ships. The lighthouse is endowed with symbolic significances by way of a conversational exchange between the narrator and $\mathrm{Mr}$ Mayman:

Sometimes, as I walked past, I would say, 'Where's the lighthouse, Mr Mayman?'

'Mrs Mayman is my lighthouse,' he would call back. 'She lights my way in this world.'

Mrs Mayman would blush as pink as her roses and smile. (pp.8-9)
After Mrs Mayman's death, Mr Mayman is initially too griefstricken to tend his garden, which becomes overgrown. However, after he gives the child narrator a lighthouse-shaped lamp which belonged to his wife, he is freed from his grief and the final illustration shows him creating a topiary lighthouse. The overemphatic signalling of this symbolism in the dialogue above, and the use of clichéd similes such as 'pink as her roses' (inappropriately attributed to the preternaturally wise and sensitive child narrator) endow the text with considerable sentimentality.

But the text is overshadowed by the cloying sweetness of the book's illustrations and design, commencing with the endpapers, with their wallpaper-like spread of cream roses. Most doublespreads are designed within a frame of flowers, with the text, in an ornately 'artistic' font, placed within a rectangular frame, resembling nothing so much as a greeting card. The colours of rose pink, gold, sage green and sky blue dominate the illustrations, but sentimentality is manifested most obviously in the close-up and medium-distance images of Mr and Mrs Mayman gazing fondly out of the page at the child narrator, who does not appear in the illustrations but who is constructed as the adored and adoring focus of the relentlessly-smiling couple (Plate 2, p.28). After Mrs Mayman's death, the gaze of the old man is averted, and it is only in the penultimate doublespread, when he looks again directly out of the page, that the reader is assured that he has recovered (in what seems in narrative terms to be remarkably short order) from his wife's death. The text, illustrations and design of The Lighthouse seek to align child readers with the feeling, responsive child narrator, but the excesses of design and illustrations draw attention to themselves.

I want now to consider three picture books which thematise child homelessness: two Australian books, Way Home (1994), by Libby Hathorn and Gregory Rogers, Space Travellers (1992), by Margaret Wild and Gregory Rogers, and Maurice Sendak's We Are AIl in the Dumps with Jack and Guy (1993). In thematic and ideological terms, homelessness is dangerous territory for creators of picture books, especially in regard to the danger of sentimentalising homelessness, or at least of representing it as an experience somewhat akin to the adult-free adventures of the Famous Five; moreover, child homelessness is related to complex social and political factors which would seem to lie outside the scope of verbal narrative in most picture books and which therefore rely on the capacity of illustrations to signal such complexity. 
Space Travellers most clearly exemplifies the tensions which exist between the socialising imperatives of picture books and the unsettling thematics of homelessness. Zac and his mother Mandy sleep in a rocket located in a playground, where Zac's imagination transforms his experience: ' $\mathrm{Zac}$ is sure he can feel the rocket zooming through the clouds, past the moon, up towards the stars' (p.6). While Rogers encodes Zac's fantasy through an image of the elongated rocket thrusting towards the stars (p.7), the text of the following page focuses on Mandy's reactions to offer a more prosaic version of the discomfort of sleeping in a rocket: '...Mandy tries to smile. She's all scrunched up and her neck aches and the nights are getting colder' (p.8). At the same time, the visual image of Mandy and Zac curled up together, Mandy's body mirroring the rounded contours of the rocket to enfold $\mathrm{Zac}$, constitutes an embodiment of the warmth and intimacy of their relationship (Plate 3 p.29). The young reader implied by the text is, I suspect, more likely to be persuaded by Zac's imaginative reconstruction of the situation than by Mandy's discomfort, especially given the tonal warmth of Rogers' palette and the soft folds of Mandy's and Zac's clothes and sleeping-bags. There are powerful tensions here between a romanticised view of homelessness and the emotional and symbolic significances of 'home'; and between top-down knowledge (of cultural, social, generic and textual practices) and the problem, for child readers, of making sense of Mandy's and Zac's predicament through a bottom-up reading which relies on a reader's capacity to decode the discourse of a particular text (see Stephens 1992, pp.29-33).

Similar tensions are obvious in the book's representation of the sociality of the group to which Mandy and Zac belong. On one hand, Simon, Ron and Dorothy are represented as unlucky in not having a rocket to sleep in; on the other, they bring to breakfast with Mandy and $\mathrm{Zac}$ reminders of a benevolent community: 'Simon has some frankfurts the butcher gave him. Ron has six bread rolls. Dorothy has a flask of tea from the hairdresser....' While Simon, Ron, Mandy and $\mathrm{Zac}$ are treated as ordinary characters who happen to be homeless, homelessness itself is variously and uncertainly inscribed, as both desirable and undesirable, 'normal' and 'abnormal', the warm glow of the illustrations affording an idealised view not present (or spasmodically present) in the text. The treatment of Dorothy, linked through her imaginings of space travel with the child $\mathrm{Zac}$, is particularly problematic; in visual terms, Dorothy might be an 'ordinary' grandmother, and her access to Zac's fantasy renders her decision to live in the rocket logical in terms of this fantasy. Again, however, top-down knowledge of the probable significance of Dorothy's 'wide, dazed smile' and of her tenuous existence as a 'bag-lady' collides with the life experience and knowledge available to implied child readers.

\section{While Space Travellers} intermittently romanticises homelessness (especially through its illustrations), I do not believe that its overall effect is one of sentimentalisation; its verbal narrative, focalised partly through Zac and partly through the narrator, does not, like that of Sophie, manipulate the reader's emotional response. It is one of the book's strengths that its representation of homeless people avoids an objectifying treatment by which the homeless function as Others to a world of people with homes and families. However, a kind of pathos results from the conflict between the two kinds of knowledge to which I have referred, and this pathos centres on the figure of $\mathrm{Zac}$, whose idealised view of life in the rocket constructs him as a Wordsworthian innocent, immune from the anxieties and insecurities which are signalled through Mandy's actions and speech.

Way Home traces the progress of a homeless boy, Shane, to his squat, together with the kitten he 
finds at the beginning of the narrative. Hathorn's narrative is constructed entirely in present tense, a strategy which exacerbates the tension of Shane's uncertain journey by refusing the reader the already-achieved closure which is normally encoded, even if subliminally, in narratives unfolded retrospectively. But the present tense also suggests the presence of a viewer mediating the story for the reader, and so controlling what can be seen and known at any point, and this places the viewer/narrator in a particularly powerful position.

Gregory Rogers' illustrations follow the text while providing a highly-charged representation of the world in which Shane is precariously located: that of a dark and enclosed cityscape in which the lighted windows of homes and shops allude to a world of domestic and relational intimacy which is denied to Shane. As Stephens notes (1994, pp.77-78), the oblique angles from which many of the illustrations are viewed serve to distance readers from events and characters, but there is a balancing pull towards empathy and towards a consolatory closure through the foregrounding of Shane's love for the kitten which constitutes a substitute for family. The illustrations offer few other compensatory signifiers, with the exception of the figure of the prostitute who calls Shane by name ('Got yourself a cat, Shane?') and who metonymically represents a world of outsiders who offer one another recognition and support. In contrast, signifiers of Shane's marginality abound: the lighted restaurant to which he has no access, pedestrians who walk towards homes or entertainment, a street sign urging adults to watch for children.

As I have said, the use of present tense endows the narrator with considerable power; as well, the narrative device of one-sided conversations in which Shane speaks to his cat underlines the narrator's presence and, through inquit-tags such as 'yells', 'laughs' and 'sings', serves to direct the reader's interpretation of Shane's speech. In another controlling move, the nominal phrases the boy called Shane' and 'the cat with no name' simultaneously encode marginality and the narrator's presence. The cat would be unnamed but for the many names it is given through narrative representations of Shane's speech; and the boy would be unnamed except for the narrator's knowledge of the boy's identity and the prostitute's greeting (p.18). Sentimentality is realised in the over-wording of references to the cat, in phrases such as: 'this clever baby thing...Such a tight little ball of fierce cat'; more than this, the symbolic linking of boy and cat (both street-fighters, fugitives, alone, endangered) allows for a slippage of reference through which these phrases might refer to Shane as well, and in this way the figure of the homeless child is, I think, sentimentalised discursively and through the controlling narrative strategies to which I have referred. The apparent contradictions of tough/ vulnerable, wild/domestic, homeless/at home, independent/ dependent, which apply to a composite figure of Shane and the cat, are mediated through a narrative voice which, in claiming exclusive access to events and characters and to the emotional significances which they encode, also claims a particular purchase upon insight and compassion.

The final illustration of Way Home locates Shane and the cat in Shane's squat, represented through Rogers' use of warm browns and oranges and through the contrast between dark frame and light-filled interior as a homely and inviting space (Plate 4, p.30). Stephens has commented on Rogers' 'heavily symbolic appropriations' (1994 p.78) of the hands of God and Adam from the Sistine Chapel ceiling. This image is shown in the book's first doublespread by way of a torn poster which reappears in Shane's squat, its fissure repaired through the picture of a kitten which signifies the healing power of self-other interaction, and is integrated with 
the domestic details of bowl and mug, rug and cushion into a 'painterly, luminous, classic "Still Life", underlining the affirmation of familiar humanist values' (Stephens 1994 p.78). Outside the warm nest of this space lies the darkness of the city, signified in the illustration's frame, and while Way Home seems to celebrate the resilience and essential humanity of the homeless boy, its use of a moody, lowering cityscape and unnamed hostile forces (the street-gang and the dog) as metonymic of an uncaring society offers a limited conceptual framework (other than a purely oppositional one) within which readers might situate the figure of Shane.

In contrast, the front cover of Maurice Sendak's We Are All in the Dumps with Jack and Guy contextualises child homelessness by representing children clad in newspapers containing headlines such as 'Leaner Times Meaner Times', 'Homeless Shelters' and, in countering signifiers, 'Kid Elected President' and 'Children Triumph'. Whereas Way Home and Space Travellers work within fundamentally realistic modes, We are all in the Dumps functions within a framework of fantasy and especially of dreamlike action sequences; yet of the three picture books it is Sendak's that most clearly signals the relatedness of individual experience to social and political contexts.
In We Are All in the Dumps, Sendak draws upon the words of two nursery rhymes 'ingeniously joined and interpreted', and invests them with significances which draw upon a range of intertextual and symbolic references. Within this discussion, I want to concentrate on Sendak's representation of the homeless child, variously referred to as 'the baby', 'a little boy with one black eye' and 'the poor little kid', whose journey from isolation to sociality constitutes the book's main narrative line. The child, as he appears on the half-title page (Plate 5, p.31), is a representative figure, both pathetic and grotesque: bald, at once ancient and infant, dressed in snow-white rags, with hands and feet of exaggerated size, protruding ears, and mouth wide open in a roar of anguish or rage. The two doublespreads which constitute the book's extended title page offer two tableaux, first of sleeping then of waking children living 'in the dumps'. Against this background the baby's movement is plotted, from a position at the far left of the spread to one at the right, where he appeals for help to Jack and Guy, the other actors in the drama (for We Are All in the Dumps is presented in strongly theatrical terms), whose rejection of his appeal (p.5) incurs the disapproval of the watching moon, which functions partly as Greek chorus, partly as deus ex machina.
The giant rats which abduct the kittens and the baby are 'ingeniously' linked with a rapacious corporate world, through the symbolism of the Trump Tower, which is silhouetted against the night sky as the rats win their game of bridge, and through the punning reference 'Diamonds are trumps' (pp.12-13). In this way, and through the visual contrast between the motley band of homeless children and the powerful presence of the rats, Sendak signals connections between corporate greed and poverty. Similarly, homelessness is pitted against the privilege encoded in the real estate references of the newspapers which the children wear, and whose headlines 'Very Smart Living', 'Mortgage Money Available' and 'Profit from our Losses' jostle ironically against 'Yard Sale' and 'Want a Kitty to Cuddle?' (p.16); here, wealth and poverty are seen as symbiotically connected, not simply as antithetical.

When, in the second of the rhymes, Jack and Guy find the baby, now 'a little boy with one black eye', Jack's initial reaction ('Let's knock him on the head') exemplifies the strange and sudden violence which characterises many traditional rhymes, but Sendak uses it to establish a narrative move which draws upon Christian iconography to align the child 
with the figure of Christ. ${ }^{1}$ After the moon (transformed into a cat) vanquishes the wolves, frees the baby and the kittens and breaks open St Paul's Bakery and Orphanage, the baby is returned to earth in a scene which echoes representations in religious art of the removal of Christ from the cross (a scene commonly referred to as the Deposition). Against the golden nimbus of the moon and with the shadow of his arm sketching the horizontal axis of the cross, the baby, his features relaxed in a death-like sleep, is lifted gently to earth by Jack. Guy, whose presence echoes the disciples who appear in many representations of the Deposition, watches perched on the moon's edge, and two kittens look out into the darkness, leading the viewer's eye to the turning page (Plate 6, p.32). The final doublespread, in which Jack sits asleep with the baby on his knee, both incorporates the child into the community of the dumps and celebrates Jack's own salvation; for in the light of the preceding image his act of love can be seen to fulfil Christ's injunction: 'Anyone who welcomes a little child...in my name welcomes me' (Matt.18.5). The last savage irony of We Are All in the Dumps has Guy saying 'And we'll bring [the baby] up as other folk do', against the background of the dumps, with the row of homeless children taking up their accustomed positions as householders without homes, in houses without walls.
Peter Neumeyer is correct in his identification of the sense of Blakean outrage which permeates We Are All in the Dumps (1994, pp.36-38), but the book's foregrounding of the social and political contexts of poverty coexists with its celebration of the robustness and tenacity of its child characters. Such an attitude is, I think, preferable to the woolly romanticism with which Space Travellers treats homelessness, and to the sentimentality of Way Home, which, in its textual control of reader subjectivity, its construction of a hostile world and its final lingering visual representation of Shane's 'home', seems to valorise a quietism which accepts child homelessness, and the contexts in which it occurs, as givens.

I noted earlier that the term 'sentimentality' works in conjunction with gendered assumptions which privilege masculine rationality over feminine emotionality, and the texts which I have discussed might seem to support a view of the sentimental as associated with the feminine, since I have argued that the female-authored texts of Sophie and Way Home manifest features of sentimentality which drive the illustrations of these books (by, respectively, Craig Smith and Gregory Rogers), and that John Burningham's Granpa and Maurice Sendak's We Are All in the Dumps with Jack and Guy are unsentimental in their encoding of emotion (the text and illustrations of The Lighthouse cancel each other out). Because women and men operate within different discursive frameworks, it is often the case that they produce and receive texts differently; however, it would take a much more extended discussion than this to explore what constitutes feminine and masculine discourse and how sentimentality in picture books relates to questions of gender. To demonstrate that sentimentality manifests in male-authored as well as female-authored picture books, I will conclude by discussing a male-authored text in which sentimentality is realised not only through discursive and narrative features but within the context of particular cultural and reading practices.

Sam McBratney and Anita Jeram's Guess How Much I Love You (1994) has since its publication become something of a marketing phenomenon, appearing as a board book, a conventional hardcovered book, as part of a package along with a stuffed toy and spawning a calendar and notepaper. McBratney's text is built around a playful competition in which parent and child try to find who most loves the other. The inequality of the competitors is encoded throughout the text by way of a series of comparisons between Big Nutbrown Hare and Little 
Nutbrown Hare, constructing the child figure as weak and small, no match for the adult's strength and knowledge; the very repetition of the names attributed to the characters slows the narrative to insist on this inequality. Such an imbalance in power relationships also works through the way in which the narrative shifts between character focalisation (through Little Nutbrown Hare) and narrator focalisation. Thus, in admiring the superior attributes of his father, Little Nutbrown Hare is seen to underscore his own inadequacies: 'Hmm, that is a lot...I wish I had arms like that....I wish I could hop like that', and the narrator's voice implies a somewhat

condescending humour at the expense of Little Nutbrown Hare, seen in the following passage: 'Then Little Nutbrown Hare had a good idea. He tumbled upside down and reached up the tree trunk with his feet. "I love you all the way up to my toes!" he said' (pp.16-17). The first sentence in this passage, occurring within a narrative pattern in which Little Nutbrown Hare's ideas are incapable of measuring up to those of his father, plays with the contrast between the expectation that Little Nutbrown Hare will fail and Little Nutbrown Hare's naive optimism; the verbs 'tumbled', with its associations of childish clumsiness, and 'reached up', which suggests the unceriain progress of Little Nutbrown Hare's movement, imply readers amused at his combination of ardour and ineptitude.

Anita Jeram's illustrations for Guess How Much I Love You evoke the English tradition, in illustrated books and picture books, in which anthropomorphized animals are rendered through watercolour and line drawings and set in the soft greens and browns of an archetypal English countryside. It is a style of pastoral which almost inevitably encodes nostalgia for a gentler past some time before the Industrial Revolution, and Jeram's illustrations are thus doubly susceptible to sentimentality, through this sense of cultural nostalgia and because they are driven by a sentimental narrative. They are 'images set down with tenderness' which exemplify the 'saccharine strand' to which Jane Doonan alludes (1994 p.167).

But it is the market-driven production of this book, and the merchandise associated with it, which is of most interest for this discussion. Booksellers have told me that while Guess How Much I Love You has been a popular choice by parents for their children, by far the largest group of buyers has been constituted by men and women buying the book as a present for a loved (adult) other. It thus finds a place within a strand of sentimental social practices concerned with romantic friendship and with communication between partners in such friendships. While in Guess How Much I Love You the choice of masculine gender constructs a father-son relationship between the two hares, this choice also allows for the interpellation of the feminine in the case of heterosexual couples sharing the book, following patriarchal traditions in which terms such as 'he' and 'mankind' are used to incorporate the feminine (while implying a normative masculine, middleclass, white male subject). A narrative involving a mother hare and her daughter or son would, I suspect, have been read as gendered in a specifically feminine way, and would have been much less likely to offer the possibility of being read as encoding heterosexual romantic love. The unequal power relationships between Little Nutbrown Hare and Big Nutbrown Hare in Guess How Much I Love You suggest that it is read as a highly conservative encoding of male-female intersubjectivities in which the figure of Little Nutbrown Hare is feminised, since the binaries of the narrative (big/small, wise/ foolish, rational/emotional, strong/weak) are precisely those which work through patriarchal discourse to privilege the masculine.

I began this discussion by referring to ideas about sentimentality as culturally 
dependent and subject to shifts and changes in social and cultural practices. Nevertheless, I believe that sentimental picture book texts tend to draw attention to the superior qualities of their narrators and/or implied authors through manipulative narrative and discoursal strategies; and that sentimentality in illustrations works in a similar way to control reader subjectivity. Because picture books are marketed to adults, they offer possibilities, such as those exploited by Walker Books in the case of Guess How Much I Love You, to work within social practices other than those connected with children. Finally, ideas about sentimentality are inextricably connected with the assumptions of the patriarchal relations which are still dominant within the institutions and practices of contemporary societies.

\section{Notes}

1. For an illuminating discussion of Sendak's intertextual references, in We Are All in the Dumps, to Christian iconography dealing with the Harrowing of Hell, see Doonan, 1994.

\section{References}

Blacklock, Dyan, and Woolman, Steven (1995) The Lighthouse. Flinders Park, Era Publications.

Bradford, Clare (1994) 'Along the road to learn: children and adults in the picture books of John Burningham', Children's

Literature in Education 25, 4, 203-211.

Burningham, John (1984) Granpa.

London, Jonathan Cape

Doonan, Jane (1994) 'Into the dangerous world: We Are All in the Dumps with Jack and Guy by Maurice Sendak', Signal 75, 155-171.

Fox, Mem, and Smith, Craig (1989) Sophie. Melbourne, Drakeford Publishing.

Graham, Judith (1990) Pictures on the Page. Sheffield, NATE.

Hathorn, Libby, and Rogers, Gregory (1994) Way Home. Sydney, Random House.

McBratney, Sam, and Jeram, Anita (1994) Guess How Much I Love You. London, Walker Books.

Munsch, Robert, and McGraw, Sheila (1997) Love You Forever. Ontario, Firefly. (This book, now in its 54th printing, has been illustrated by various artists.)

Neumeyer, Peter (1994) 'We Are All in the Dumps with Jack and Guy: Two nursery rhymes with pictures by Maurice Sendak', Children's Literature in Education 25, 1, 29-40.

Sendak, Maurice (1993) We Are All in the Dumps with Jack and Guy. New York, HarperCollins.

Stephens, John (1992) Language and Ideology in Children's Fiction. London, Longman.

Stephens, John (1994) 'lllustrating the landscape in Australian children's picture books', in Wendy Parsons and Robert Goodwin (eds), Landscape and Identity: Perspectives from Australia. Adelaide, Auslib Press, pp. 69-83.

Watson, Victor (1996) 'Imaginationing Granpa - journeying into reading with John Burningham', in Victor Watson and Morag Styles (eds) Talking Pictures: Pictorial Texis and Young Readers. London, Hodder \& Stoughton.

White, Richard (1981) Inventing Australia: Images and Identity 16881980. Sydney, Allen \& Unwin.

Wild, Margaret, and Rogers, Gregory (1992) Space Travellers. Gosford, Ashton Scholastic.

Acknowledgements

Plate 1 is taken from Granpa by
John Burningham. Published by Jonathan Cape, London in 1984. Copyright @ 1984 by John Burningham.

Plate 2 is taken from The Lighthouse by Dyan Blacklock, author, and Steven Woolman, design and illustration. Published by Era Publications, 1995. Text @ Dyan Blacklock, 1995. Illustration (c) Era Publications, 1995. Reproduced with permission.

Plate 3 is taken from Space Travellers by Margaret Wild, author, and Gregory Rogers, illustrator. Published by Ashton Scholastic, Gosford N.S.W'. in 1992. Text copyright $(1)$ Margaret Wild, 1992. Illustrations copyright (C) Gregory Rogers 1992.

Plate 4 is taken from Way Home by Libby Hathorn author, and Gregory Rogers, illustrator. Published by Mark Macleod Books, Random House Australia in 1994. Text copyright $\odot$ Libby Hathorn 1994. Illustrations copyright $($ ) Gregory Rogers 1994. Reproduced with permission.

Plates 5 and 6 are taken from $W e$ Are All in the Dumps with Jack and Guy by Maurice Sendak. Published by HarperCollins Publishers / Michael di Capua Books in the United States of America in 1993. Copyright (C) 1993 by Maurice Sendak.

\section{Biographical Note}

Clare Bradford teaches children's literature and literary studies at the Burwood campus of Deakin University. Her main research and writing interests are in picture book and the relationships between literary theory and children's literature. Her most recent publication is Writing the Australian Child. 
吝

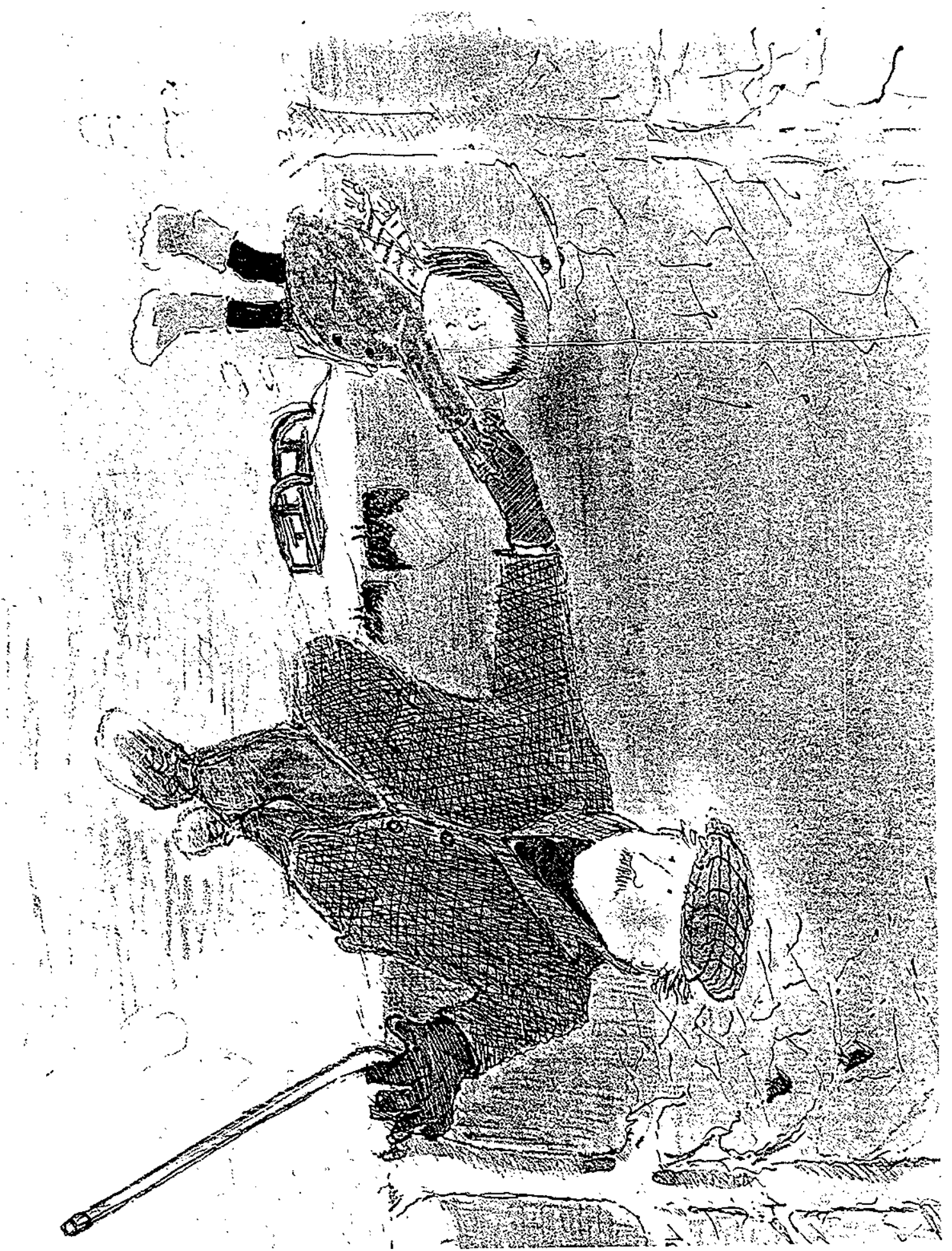




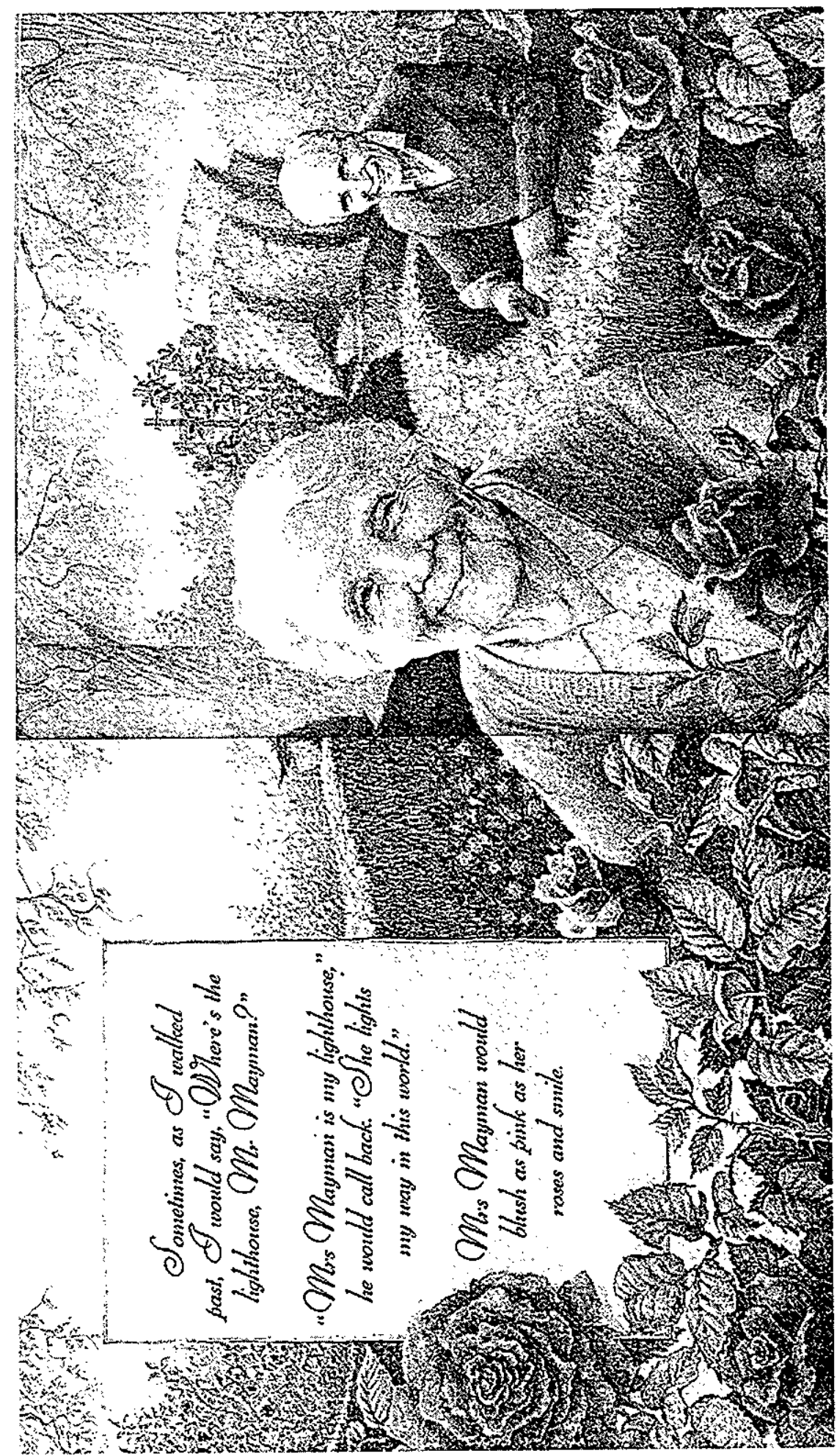




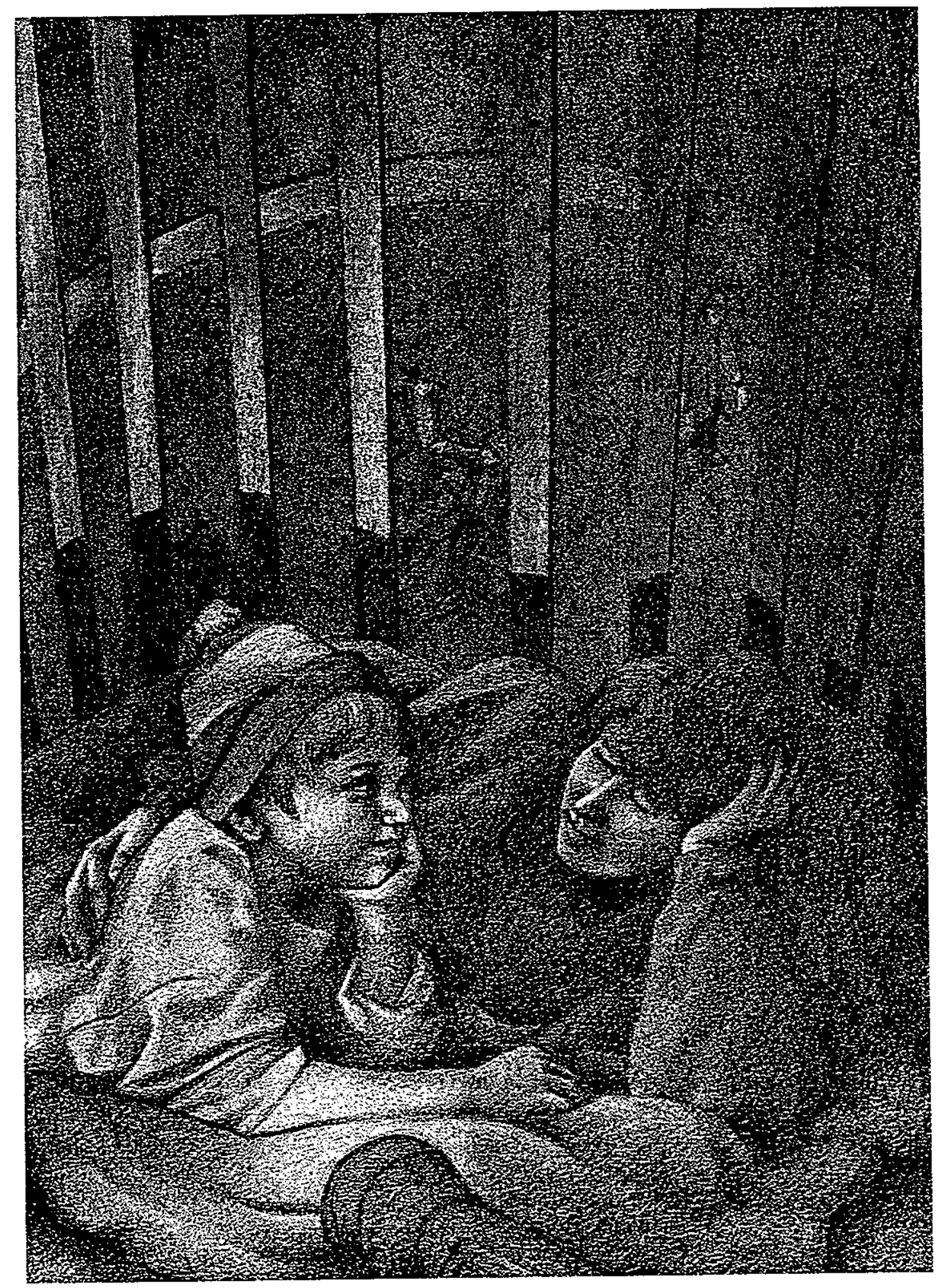

Plate 3

Papers 7: 31997 


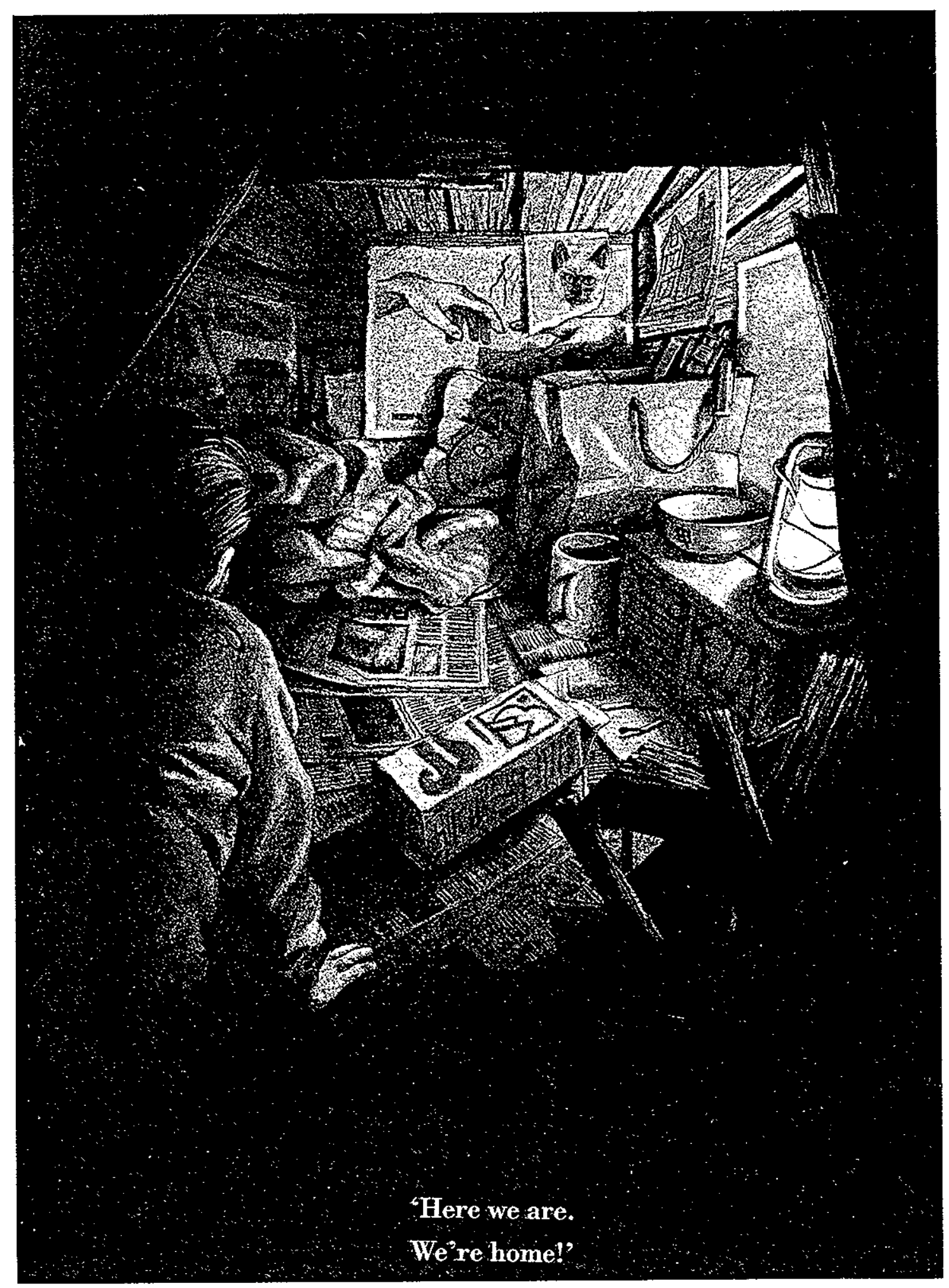

Plate 4 


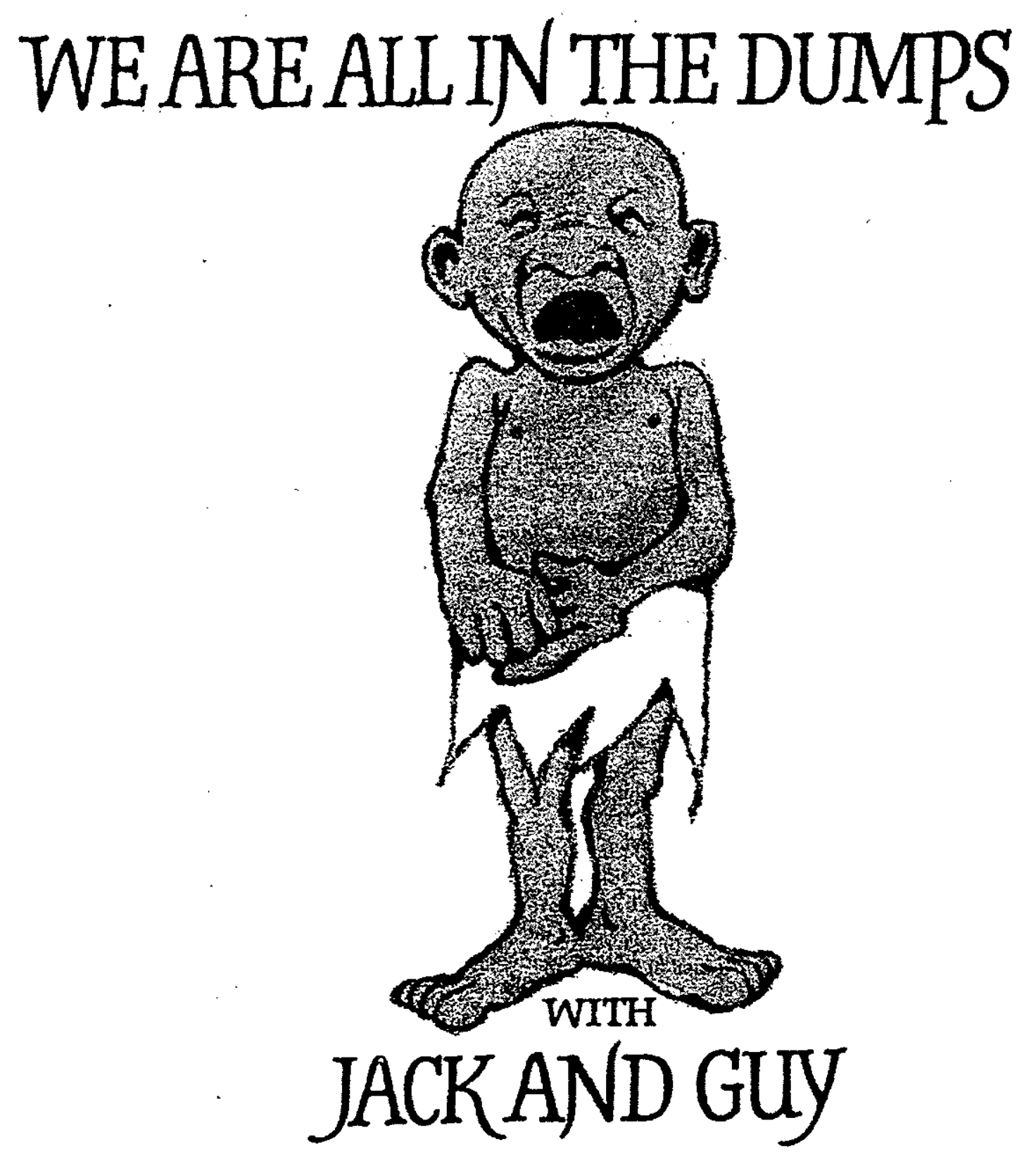

Plate 5 


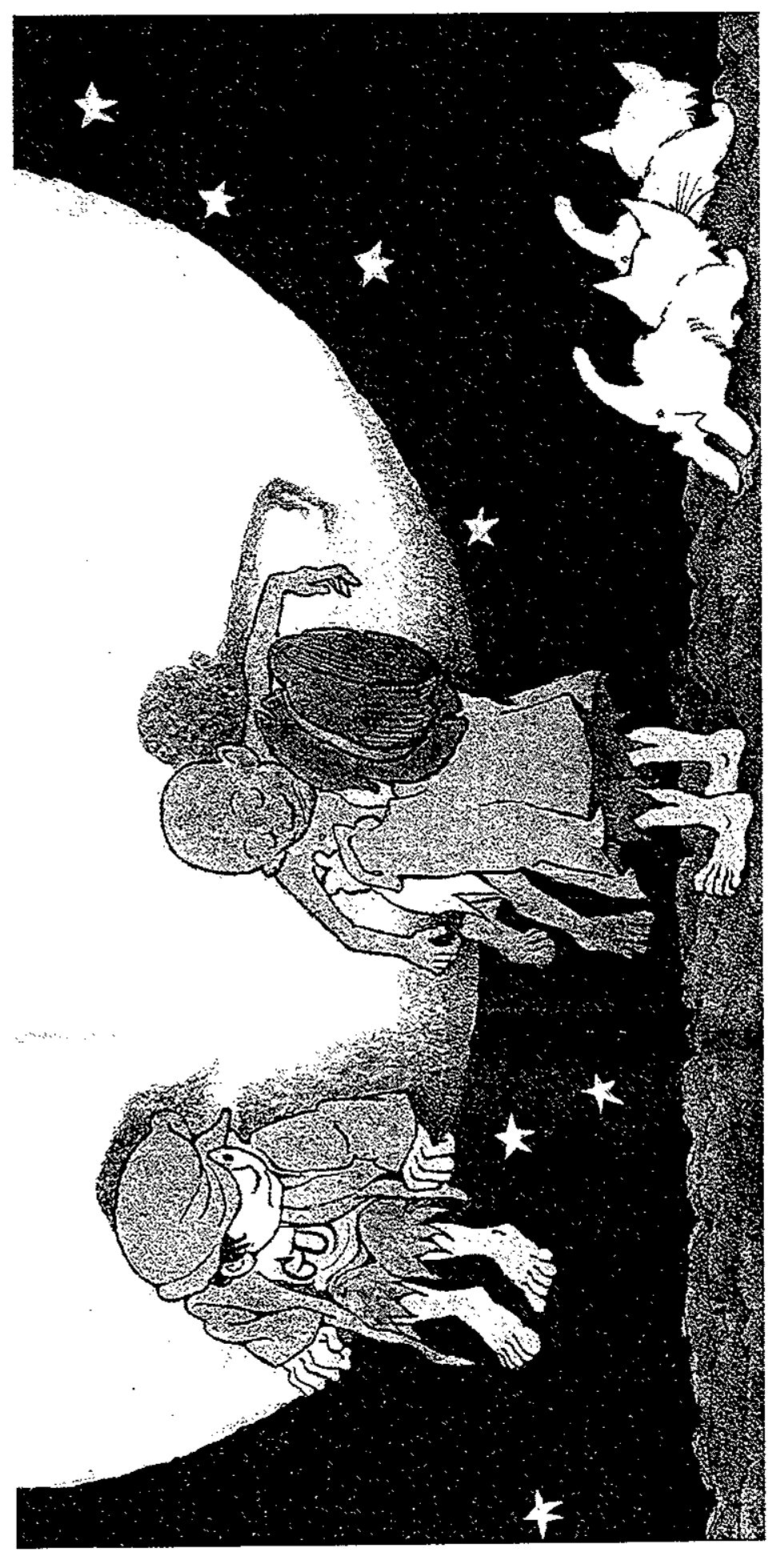

$b$
$\frac{8}{0}$
$\frac{8}{0}$ 